\title{
Element transfer study for rutile based flux constituents by taguchi analysis in submerged arc welding
}

\author{
Aditya Kumar* and Sachin Maheshwari \\ ${ }^{1}$ Dept. of MPA Engg., NSIT, Sector-3, Dwarka, New Delhi-78 \\ *Email: aditya_rathihere@yahoo.com
}

\begin{abstract}
A rutile based flux system was designed consisting of $\mathrm{TiO}_{2}-\mathrm{Al}_{2} \mathrm{O}_{3}-\mathrm{CaO}$. Taguchi $\mathrm{L} 9$ orthogonal array was used to design the flux system for submerged arc welding. Three constituents of flux were varied, with their three levels such as, $\mathrm{NiO}, \mathrm{MnO}$ and $\mathrm{MgO}$. At $32 \mathrm{~V}$ open circuit voltage, nine experiments were performed for bead on plate arrangement. Element transfer study was analyzed for rutile based flux constituents and basicity index of the flux. Weld carbon content increases because of low oxygen content. This happens due to presence of Mno in the flux. Silicon content decreases in weld metal because of $\mathrm{CaF}_{2}$ present in the flux. Copper content also decreases in the weld metal. Sulphur content was almost negligible, whereas phosphorus content decreases, because of transfer into the slag during slag metal reaction.
\end{abstract}

Introduction: Submerged arc welding is the process that consume electrode along with the agglomerated flux. The composition of the flux plays an important role to make a welded portion, stronger in terms of mechanical strength. During the welding process flux converts into weld metal and the slag. The slag covers the weld zone and it serves two purposes one is to protect the weld zone from atmospheric oxidation and another it also acts as heat barrier, to provide the better penetration. The main constituent of the flux is $\mathrm{TiO}_{2}$. The main aim of titanium oxide is used to enhance the impact strength of the weld metal.

Objective: The main objective of the study was to study the transfer of elements from flux into weld metal and slag. The voltage condition was kept constant at $32 \mathrm{~V}$. The flux constituents were varied in different proportions to find the effect of each based on the basicity index of the flux. Basicity index of the flux decide the nature of the flux whether the flux is acidic, basic or neutral.

The variation of Mn Figure 1 shows that at 32 volt, the Mn content varies from $0.3 \%$ to
$0.58 \%$, The possible reason may be the transfer of $\mathrm{Mn}$ to the slag. The $\mathrm{Mn}$ reacts with $\mathrm{SiO}_{2}$ and forms Manganese silicate, which may be transferred to the slag because it is more soluble in the slag. The second reason may be the evaporation of $\mathrm{Mn}$ as it is vaporized easily.

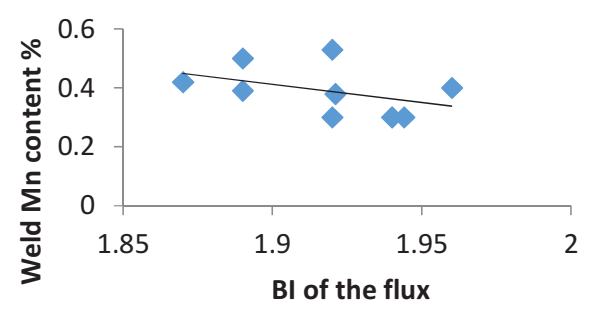

Figure 1: Weld Mn Transfer

The carbon content as shown in Figure 2 increases hardness and tensile strength but it is not supposed useful for impact strength. This increases due to the low oxygen in weld.

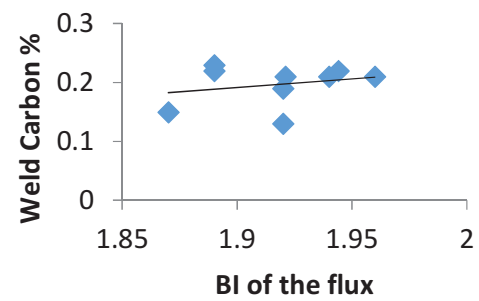

2: Weld Carbon Transfer

Figure

During the welding process flux converts in the weld metal and the slag. The slag covers the weld.

\section{References}

1. T.H.North, H.B.Bell, A.Nowicki and I.Craig. The Welding journal. pp - 63-s- 75s, 1978.

2. U.Mitra and T.W. Eagar, Metallurgical transactions A, Vol.15A, pp:-217-226,1984.

3. P.Kanjilal, T.K.Paland and S.K. Majumdar, Welding Journal . Vol.-86,pp:135s-145s.2007 